\title{
Effect of Up-Down Stairs Exercise and Hurdle Jump on Limb Muscle Explosive Power of Volleyball Players
}

\author{
YuniAstuti* Erianti \\ Sport Education Program \\ Faculty of Sport Science \\ Padang State University \\ Padang, Indonesia \\ yuniastuti@fik.unp.ac.id
}

\begin{abstract}
The purpose of this study was to determine the effect of exercise up and down the stairs and jump the hurdle drills on the ability of leg muscle explosive power volleyball club players. This type of research is experimental that involved 14 male volleyball players. Data were analyzed with descriptive and inferential statistics with dependent samples $t$ test formula. Based on the analysis of the data that the first hypothesis turns out, there is no significant influence exercises up and downstairs to the ability of leg muscle explosive power, to find $t$ at 4.36 higher than the value ttabel 2.45. Furthermore, the second hypothesis there is no significant influence of hurdle jump exercise on leg muscle explosive power because it was found to 14.14 higher than the value ttabel 2.45. While the third hypothesis there is no significant difference between the effects of exercise up and down the stairs and jump the hurdle drills on the ability of leg muscle explosive power volleyball club players SMK 1 Solok Selatan, $t=0,2,05>$ table $=2.45$.

Keywords — exercise, limb muscle, volley ball
\end{abstract}

\section{INTRODUCTION}

Sport desperately needs an integrated coaching and training, so that later can result in players who excel and be the name of either local, national or international. For coaching achievement requires a concerted effort to produce a quality player so it can be the name of the region, the nation and the state.

In SMK 1 Solok Selatan has made the promotion and development of sports, including volleyball game sport. Volleyball coaching and sport development was followed by learners, special student son who has a talent and interest in the sport of volleyball. The purpose of the volleyball coaching is to achieve maximum performance.

Based on the overview of the achievements of the players SMK 1 Solok Selatan, the author got his information from teachers penjasorkes as coach and observations, as well as the observation of the authors assume that the defeat suffered by the player SMK 1 Solok Selatan in a competition between schools due to the technical ability to play such as engineering smash volleyball, servicing jump (jump serve) and blokc not control well, meaning that their jumping ability is still low so many dropped points (points).

We know that a person to be able to hit a smash, servicing jump (jump serve) and block all of the technique is well supported by the ability to jump vertically, in order to grab the ball at the highest point on the net, so that the ball can be directed in areas difficult to be accepted by player of the opposing team. "Likewise with servicing jump, the higher the ball is hit then the likely course of the ball more sharply and at the time of the attack blokc to retain the ball right punch smash that is supported by the ability to jump, so that the ball can be anticipated that not passing to area defense did blokc" [1].

Based explained above, it is necessary "volleyball players have the ability of leg muscle explosive power".[2] who say the explosive power is the "ability to cope with the load / barriers with a high speed of muscle contraction. "Thus it can be interpreted that the leg muscle explosive power is the ability to cope with the load of leg muscle with high muscle contraction, to do some of the techniques that require volleyball vertical jump" [3].

It is not easy for a person to have the ability of leg muscle explosive power well, because one of the factors can be influenced by exercise. Exercise is a process of training to improve the quality of athletes / players are carried out systematically, repeatedly, and the longer the load is increasing in accordance with the objectives to be achieved. Plyometrics exercise is one form of exercise that can increase leg muscle explosive power, sepertia exercise up and down stairs, jump over benches, jump rope (skiiping), exercise up and down the bench, and exercise hurdle jump, and jump exercises to box.

All forms of exercise that has been stated above, can improve the ability of leg muscle explosive power volleyball club players SMK 1 Solok Selatan. With the increasing ability of leg muscle explosive power of the volleyball players, this may raise some technical ability in volleyball game. Therefore, the authors conducted research regarding the ability of explosive power leg muscle, and in accordance with the problem as the authors see in the field that the authors suspect a failure in some engineering attack is caused by the ability to jump vertically due to the ability of the explosive power of leg muscles club players volleyball SMK 1 South Solok still low.

Leg muscle explosive power is a combination of strength and speed or the ability to utilize energy in a fast tempo. The stronger the leg muscle explosive power a volleyball player the higher results. Because of leg muscle explosive power is the result of a combination of strength and speed that requires personnel fully briefed when jumping. With the leg muscle explosive power that will result in a better performance. For necessary exercises 
that can increase the explosive power of one exercise leg muscles up and down the stairs.

Exercise up and down stairs is one form of exercise plyometrik expected to increase the ability of leg muscle explosive power using the weight as the training load. In this form of exercise up and down the stairs where players are expected to jump by using two-foot pedestal and pedestal down with two legs, which will form the muscles of the legs are good, which can generate explosive power leg muscles to leap great and others. In accordance with the above description, it is suspected that by giving up stairs and down stairs exercise can improve the ability of leg muscle explosive power volleyball club players SMK 1 Solok Selatan.

In enhancing the ability of leg muscle explosive power, should be given in the form of exercise jumpjump, so as to be given a form of exercise that can jumpjump shape leg muscles which can increase the ability of leg muscle explosive power. One form of exercise is the jump-jump exercise hurdle jump, jump a hurdle which the exercise is also one form of exercise plyometrik expected to increase the ability of leg muscle explosive power using the weight as the training load. Exercise hurdle jump leap that hurdle drills, where players do exercises leap with wicket-wicket pass a small amount of 4 small wicket and $60 \mathrm{~cm}$ high with pedestal using two legs, so as to form the leg muscles which can increase leg muscle explosive power needed to make the leap and sebagianya. Based on the description that has been stated above, it is expected that by giving the exercise hurdle jump repeatedly and increased load can increase leg muscle explosive power volleyball club players SMK 1 Solok Selatan.

1. Differences in effects of exercise up and down the stairs and jump the hurdle of the ability of leg muscle explosive power in volleyball players SMK 1 Solok Selatan.

Leg muscle explosive power is needed in some of the implementation techniques volleyball sports games such as jumping to smash (spike), conducting dam (block), servicing jump (jump service) and so forth. If a player who has a leg muscle explosive power is good, it can produce a good jump anyway. For that leg muscle explosive power should be increased through exercises that can increase leg muscle explosive power that is through plyometrics exercises like riding down stairs and jump the hurdle exercises.

Both of these exercises are both aimed at improving the explosive power leg muscle, but the form of the implementation of the exercise and the media used in the exercises are different, so that the leg muscle explosive power results obtained from the two forms of the exercise is thought to have differences. With the difference in the execution of the exercise, the researchers wanted to prove through research differences in the effects of exercise into two, and wanted to prove efficient and effective to increase the ability of leg muscle explosive power volleyball club players SMK 1 SolokSelatan.

\section{RESEARCH METHODOLOGY}

Research This includes the type of quasiexperimental, which in this study is intended to reveal the cause and effect. The sampling technique is done by total sampling technique, the entire population sampled, then the number of samples is 14 people. Data was collected using vertical jump test using the formula lewisnomogram. Data were analyzed using t-test the mean difference.

\section{RESULTS}

\section{Effect of Exercise Up Down Stairs Explosive Muscle Power Of Limbs Ability Players Volleyball club SMK 1 Solok Selatan \\ a. Initial tests Explosive Muscle Power Limbs}

Based on the results of the initial test data of leg muscle explosive power of 7 players, before being given treatment with exercise up and down stairs obtained average values (mean) is 91.52, the standard deviation of 10.19. The highest score was 104 and the lowest score is 72. While the measurement distance (range) is 32 and a middle value (median) is 88 . Distribution of the results of the initial test data before the leg muscle explosive power given exercises up and down stairs, can be seen in table 1 .

Table 1.Distribution Results of Preliminary Data Explosive power Leg Muscles

\begin{tabular}{|c|c|c|}
\hline $\begin{array}{c}\text { Class } \\
\text { Interval }\end{array}$ & $\begin{array}{c}\text { Absolute } \\
\text { Frequency }\end{array}$ & $\begin{array}{c}\text { The Relative } \\
\text { Frequency }\end{array}$ \\
\hline $94-104$ & 3 & 42.86 \\
\hline $83-93$ & 3 & 42.86 \\
\hline $72-82$ & 1 & 14.29 \\
\hline total & 7 & 100 \\
\hline
\end{tabular}

Based on the description of scoring on the results of the test data beginning explosive power leg muscle player's club volleyball SMK 1 Solok Selatan before being given treatment with exercise up and down stairs has been stated above, the players found volleyball that has explosive power leg muscle with scores in the top group the average is 4 people $(57.14 \%)$ and the scores in the average group no one is sure who memilikiknya as for the below average group score found as many as 3 people $(42.86 \%)$.

\section{b. Final Test Explosive Power Leg Muscles}

Based on the results of the final test data of leg muscle explosive power after being given treatment with exercise up and down the stairs, then we obtain the average value (the mean) is 100.33 , the standard deviation is 8.29. Then obtained the highest score was 110 and the lowest score is 85 . While the measurement distance (range) is 25 and a middle value (median) is 98 . Furthermore, the distribution of the results of the final data after being given treatment with exercise up and down steps to increase the explosive power of the leg muscles, seen in table 2 . 
Table 2. Power distribution Final Results Data Burst Leg Muscles

\begin{tabular}{|c|c|c|}
\hline $\begin{array}{c}\text { Class } \\
\text { Interval }\end{array}$ & $\begin{array}{c}\text { Absolute } \\
\text { Frequency }\end{array}$ & $\begin{array}{c}\text { The Relative } \\
\text { Frequency }\end{array}$ \\
\hline $102-110$ & 3 & 42.86 \\
\hline $93-101$ & 3 & 42.86 \\
\hline $84-92$ & 1 & 14.29 \\
\hline total & 7 & 100 \\
\hline
\end{tabular}

Based on the description of scoring on the results of the test data end explosive power leg muscle of 7 players club volleyball SMK 1 Solok Selatan after a given exercise up and down the stairs as mentioned above, the players found volleyball that has explosive power leg muscle with the score at above average group is 3 people $(42.86 \%)$ and volleyball player who memilikik score in the group average of only one person (14.29\%). As for the below average group score is found that 3 people $(42.86 \%)$.

2. Effect of Hurdle jump Against Against Explosive Muscle Power Capability Limbs

\section{a. Initial tests Explosive Muscle Power Limbs}

Based on the results of the initial test data of leg muscle explosive power of 7 players volleyball club SMK 1 Solok Selatan before being given treatment with hurdle jump, the value of the average (mean) is 99.46, the standard deviation was 7.27, the highest score 107 and the lowest score of 86 . While the measurement distance (range) is 22 and a middle value (median) is 97. Furthermore, the distribution of the results of the initial data of leg muscle explosive power before being given treatment with hurdle jump, can be seen in table 3 below:

Table 3.Preliminary Test Results Data Distribution Explosive Muscle Power

\begin{tabular}{|c|c|c|}
\hline Class Interval & $\begin{array}{c}\text { Absolute } \\
\text { Frequency }\end{array}$ & $\begin{array}{c}\text { The Relative } \\
\text { Frequency }\end{array}$ \\
\hline $100-107$ & 5 & 71.43 \\
\hline $92-99$ & 1 & 14.29 \\
\hline $84-91$ & 1 & 14.29 \\
\hline total & 7 & 100 \\
\hline
\end{tabular}

based ondescription of scoring the results of the initial test data of leg muscle explosive power before being given a jump that hurdle has been stated above, it is found that volleyball players have scores above average group was 5 people $(71.43 \%)$ and score in the group average no one is sure players get it. As for scores below average group found that 2 people $(28.57 \%)$.

\section{b. Final Test Explosive Power Leg Muscles}

Based on the results of the final test data of leg muscle explosive power of 7 players volleyball club SMK 1 Solok Selatan, after being given a jump hurdle values obtained average (mean) is 109.44 , the standard deviation is 8.30 , the highest score of 114 and a score 74 . While the lowest measurement distance (range) is 26 and a middle value (median) is 94 . Furthermore, the distribution of the final test data results of leg muscle explosive power volleyball club players SMK 1 Solok Selatan after being given treatment with exercise hurdle jump, can be seen at table 4.

Table 4. Final Test Results Data Distribution Power Explosive Leg Muscles

\begin{tabular}{|c|c|c|}
\hline Class Interval & $\begin{array}{c}\text { Absolute } \\
\text { Frequency }\end{array}$ & $\begin{array}{c}\text { The Relative } \\
\text { Frequency }\end{array}$ \\
\hline $111-119$ & 3 & 42.86 \\
\hline $102-110$ & 3 & 42.86 \\
\hline $93-101$ & 1 & 14.29 \\
\hline total & 7 & 100 \\
\hline
\end{tabular}

Based on the description of scoring on the end of the test data of leg muscle explosive power after being given treatment with exercise hurdle jump that has been stated above, it is found that volleyball players have a leg muscle explosive power with a score above average group was 5 people $(71,43 \%)$ and score in the group average, not a single person who has it. As for scores below average group found that as many as 2 people (28.57\%).

Results of testing the first hypothesis turns up and down stairs exercise significant influence on the increase of leg muscle explosive power volleyball club players SMK 1 Solok Selatan, because it was found t 4.36> 2.45 ttabel. This means that by providing exercise up and down stairs on a volleyball club players SMK 1 Solok Selatan, to give effect to an increase in leg muscle explosive power.

Results of testing the second hypothesis turned out to exercise hurdle jump significantly influence the ability of leg muscle explosive power volleyball club players SMK 1 Solok Selatan, because it was found thitung 14.14>ttabel 2.45. This means that the exercise hurdle jump can enhance the ability of leg muscle explosive power.

The third hypothesis proposed in this research is There is a significant difference between the exercise up and down stairs with exercise hurdle jump on the ability of leg muscle explosive power volleyball club players SMK 1 Solok Selatan. To test the hypothesis used formula coefficients mean difference test or test - t. As for determining whether the coefficient obtained by the formula $\mathrm{t} t$ significant or not then compared with ttabel. The results of the analysis of the coefficient obtained $t=$ $2.05>\mathrm{t}$ table $=1.78$. Thus it can be concluded that if the value obtained from the $t$ greater than the value obtained from ttabel the hypothesis proposed in this study received empirical truth.

Based on the above, it is clear that there are differences between exercise significant influence up and down the stairs with a jump hurdle to improving the ability of leg muscle explosive power of the player at the end of the exercise. Furthermore, from the calculation of the average value of the two sample groups using different exercises are exercises up and down stairs obtained average values (mean) it is 100.33 and the exercise hurdle jump obtained or the average value (mean) it is 109.44 . 


\section{DISCUSSION}

Based on the results of testing the first hypothesis is proven that exercise up and down the stairs to give effect to the ability of leg muscle explosive power volleyball club players SMK 1 Solok Selatan. The magnitude of the effect is equal to 8.81, it is known from differences in average values (mean) of the initial test before being treated workout up and down stairs is equal to 91.52 and after being given a treatment derived average value (mean) of 100, 33 with a value of $t \mathrm{t}$ analysis or 4.36 greater than the value ttabel 2.45 .

Based on the description above, it is clear that the exercise up and down the stairs given to the volleyball players repeatedly during 16 sessions, can improve the ability of leg muscle explosive power. [1] says that "exercise is a process pengelolahan or application of training materials such as movement skills in the form of repeated implementation and through the varied demands".

In accordance with these opinions, it can be said that the application of exercise climbing stairs and down stairs as training material for a process of training and implementation skills of motion is done repeatedly. Movement up and down the stairs begins with a standing position facing the stairs, a slight bend of the knee joint \pm $135^{\circ}$, the two arms are next to the body, followed by a second bendable joints $\pm 90^{\circ}$ and then reject the two-foot pedestal to the top of the stairs, legs collectively the same jump up and down stairs with a landing two feet bersamaaan into place, landing as soon as possible to its original position to continue with the same movement next.

Exercise up and down the stairs is a simple form of exercise plyometrics to improve the ability of leg muscle explosive power. Judging from the movement jump with two feet from one ladder to another staircase sourced from leg muscle power. By doing up and down the stairs muscles undergo changes, such asthe muscles of the legs and arms. It has been suggested that by doing exercises up and down stairs is likely to increase in the ability of leg muscle explosive power and hand muscles.

Furthermore, based on the results of testing the second hypothesis is proven that the exercise hurdle jump can give effect to the ability of leg muscle explosive power volleyball club players SMK 1 Solok Selatan which is equal to 9.98. It dketahui of differences in the average value (the mean) in the initial tests before being treated hurdle jump and the average value (mean) after being given treatment, with a value of $\mathrm{t}$ analysis or $\mathrm{t}$ greater than the value ttabel, and the truth is received empirically ,

Based on the findings of the research that has been described above, it can be interpreted that by providing exercise hurdle jump systematically, and loads a regular physical, directed, gradually increased, and done repeatedly is time, then this may increase working leg muscles, and the ability of leg muscle explosive power. Hurdle jump is plyometrics exercises that use the body's own weight as the training load.
Hurdle jumpoften interpreted jump by using obstacles or small wicket as high as $60 \mathrm{~cm}$. But according to train athletes jump wicket beginner, choose wicket mock height lower hip. This exercise will be done by passing several rows of obstacles arranged in height berberbeda. In workout hurdle jump leg muscles, which are crucial for increasing the working leg muscles, especially the quadriceps's muscle or musculusfemoris, musculus's bicep femoris, musculus gastrocnemius and anterior musculustibialis.

More clearly seen when the leg muscles work jumped onto the pedestal across goal by using both feet and both hands simultaneously swing when landing immediately jump to the top of the obstacles require leg muscle strength, the stronger leg muscles so the sooner put out feet up. While the leg muscle explosive power is defined as the ability of a combination of strength with speed is realized in the form of the muscle's ability to cope with the burden of high contraction speed, for example when a volleyball player smash, jump serve and also at the time of blokc. Therefore, the ability of leg muscle explosive power is one of the elements of physical conditions that must be owned by a volleyball player.

Differences influence research results suggest that there are significant differences exercise influence up and down stairs and jump the hurdle drills on the ability of leg muscle explosive power, and accepted as true by empirical. Thus it can be said that both forms of exercises can be given to players volleyball though different influences. Both forms of this exercise's goal is to increase the ability of leg muscle explosive power. This means that both forms of exercise that is given is a form of plyometrics exercises to improve muscle power exsplosive.

But despite the significant differences between these two forms of the exercise, but biila seen from the difference arithmetic mean value (mean) of the initial test of leg muscle explosive power of the exercise up and down stairs and finally tests the increase of 8.81. As for the initial test of leg muscle explosive power jump hurdle exercise group gained an average count value (mean) of the initial test and the test ended, an increase of 9.98. This means that the exercise hurdle jump higher increase compared with the exercise going up the stairs and down the stairs.

As described in the previous section that exercise climbing the stairs down stairs and jump the hurdle exercises a form of plyometrics exercises. In accordance says that "plyometrics are specific exercises that train your muscles to produce maximum power more quickly. The resulting maximum strength in a very fast time called exsplosive power or explosive power " [2].

In this study is the enhanced explosive power leg muscle explosive power, which is having an important role in several techniques such as engineering smash volleyball, servicing jump (jump service), and block. Of course, volleyball players are required to do exercises that can increase leg muscle explosive power, one would be unable to jump vertically as high as possible to hit the ball over the net at the highest point unsupported by the ability 
of leg muscle explosive power. Furthermore, "Given the importance of sports activities to improve physical fitness, it is necessary to empower sports as early as possible both at school and to the wider community" [4].

\section{CONCLUSION}

Explosive power arm muscles have a significant relationship with the service capabilities on volleyball and received kebenaranya empirically, and contributed $18.06 \% .2$ ) The concentration does not have a significant relationship with the service capabilities on volleyball and accepted as true by empirical, 3) Explosive power arm muscles and concentration jointly have a significant relationship with the service capabilities on volleyball and accepted as true by empirical, and contribute amounting to $21.34 \%$.

\section{REFERENCES}

[1] M. N. A. Setiawan. "Increasing Aerobic Durability Skill by Practicing Extensive Interval Method for Volleyball Athlete in Rokan Hulu Regency", Applied Science and Technology, vol. 2, no. 1, pp. 129-131, February. 2018.

[2] Syafruddin." Sports Coaching Science". Padang: UNP Press. 2011, pp. 36.

[3] Erianti. Textbook volleyball. Padang: Nikken - Padang State University. 2011.pp. 17

[4] Z. Zulbahri, "Tingkat Kemampuan Daya Tahan Jantung dan Pernafasan Mahasiswa Pendidikan Olahraga dan Kesehatan Universitas Pasir Pengaraian", Gelanggang Olahraga: Jurnal Pendidikan Jasmani dan Olahraga, vol. 3, no. 1, pp. 96-101, Oct. 2019. 